\title{
A Case of Eosinophilic Esophagitis With Food Hypersensitivity
}

Nam In Kim, $M D^{1}$, Yunju Jo, $M D^{2 *}$, Sang Bong Ahn, $M D^{2}$, Byoung Kwan Son, $M D^{2}$, Seong Hwan Kim, $\mathrm{MD}^{2}$, Young Sook Park, $M D^{2}$, Sang Hoon Kim, $M D^{2}$ and Jong Eun Ju, MD

${ }^{1}$ Center for Health Promotion, Samsung Medical Center, Sungkyunkwan University School of Medicine, Departments of ${ }^{2}$ Internal Medicine and

${ }^{3}$ Pathology, Eulji University School of Medicine, Seoul, Korea

Eosinophilic esophagitis (EoE) is a disorder characterized by isolated eosinophilic infiltration of the esophagus with esophageal symptoms. Although some patients with EoE are related to food hypersensitivity, it is hard to identify causative foods. This report describes a case of EoE with dysphagia. A 28-year-old man presented with dysphagia and substernal discomfort for 15 days. He had taken a protein complex for 2 months. Endoscopy showed several linear furrows and multiple mucosal nodularities on the lower and mid esophagus, and the biopsies of esophagus revealed marked eosinophil infiltration in the mucosa. The skin testing for the protein complex was positive. The patient was successfully treated with withholding treatment.

(J Neurogastroenterol Motil 2010;16:315-318)

\section{Key Words}

Eosinophils, Esophagitis, Food hypersensitivity, Withholding treatment

\section{Introduction}

Eosinophilic esophagitis ( $\mathrm{EoE})$ is a disorder characterized by isolated eosinophilic infiltration in esophageal mucosa. It was generally diagnosed to children, rarely occurred to adults. However, recently EoE is rapidly increasing in adults. ${ }^{1}$ Since the first case was reported in 2002, ${ }^{2}$ several cases have reported after 2008 in Korea. ${ }^{3,4}$ In a single center study of 108 Korean patients who had dysphagia and refluxed symptoms, $1.8 \%$ of those patients were afflicted with EoE. ${ }^{5}$ Another study informed that $0.4 \%$ of patients were diagnosed as EoE among 1,609 people who underwent biopsies of esophageal mucosa. ${ }^{6}$ Both reports shows that the EoE is a disease not just for western population but also for Asian including Korean. ${ }^{6}$

The cause of EoE is not well understood. However, most patients with EoE have allergic disorders such as food allergy, atopic dermatitis, asthma or allergic rhinitis, ${ }^{7}$ and improve by corticosteroid treatment. ${ }^{8}$ So it is predicted that the EoE is highly related to allergy. Through the withholding treatments based on the amino acid based formula and 6 most common allergen elimination diet after allergic evaluation, clinical and histological improvement was made in $50 \%$ to $90 \%$ of patients, which resulting food allergens are primary causes of EoE. ${ }^{9-11}$ However, the causative

Received: May 29, 2010 Revised: June 1, 2010 Accepted: June 1, 2010

(c) This is an Open Access article distributed under the terms of the Creative Commons Attribution Non-Commercial License (http://creativecommons. org/licenses/by-nc/3.0) which permits unrestricted non-commercial use, distribution, and reproduction in any medium, provided the original work is properly cited.

*Correspondence: Yunju Jo, MD, PhD

Department of Internal Medicine, Eulji University College of Medicine, Eulji General Hospital, 14 Hangeulbiseok-gil, Nowon-gu, Seoul 139-711, Korea

Tel: +82-2-970-8624, Fax: +82-2-970-8621, E-mail: jyj1138@eulji.ac.kr

Financial support: None.

Conflicts of interest: None. 


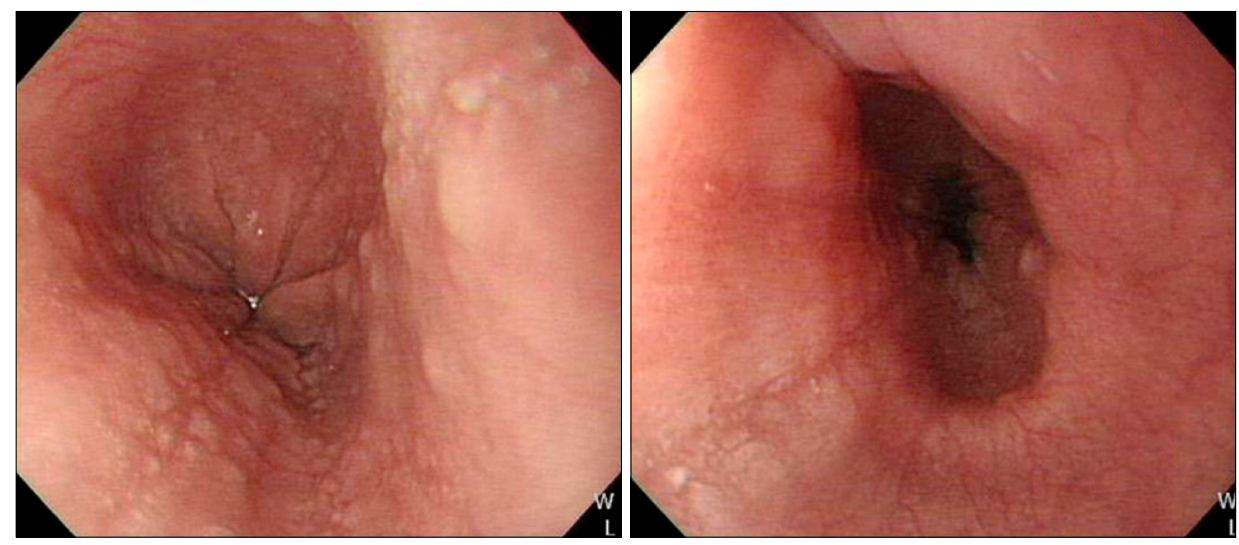

Figure 1. Endoscopy shows some linear furrows and multiple mucosal nodularities on the lower and mid esophagus.

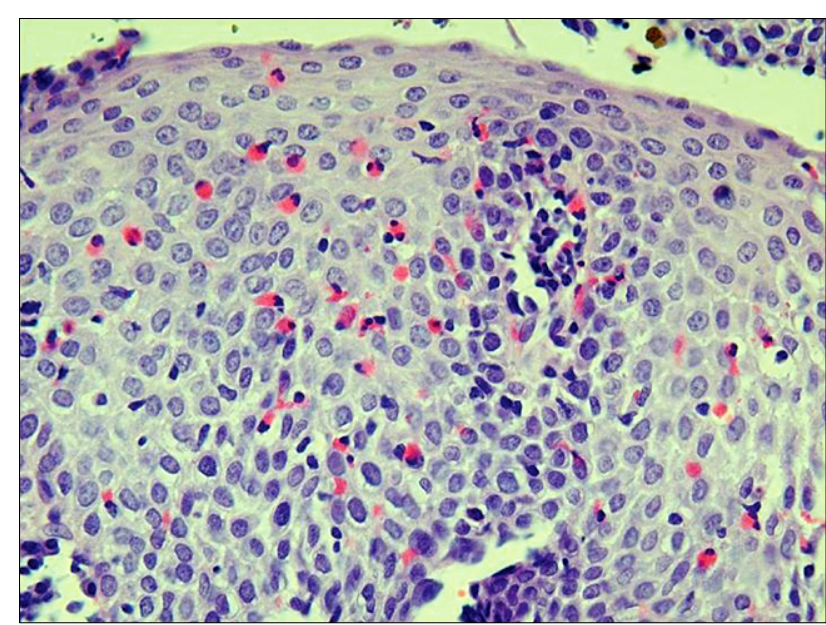

Figure 2. Microscopic finding of the esophagus shows a heavy eosinophilic infiltration, $>20$ eosinophils per high power field $(\mathrm{H} \& \mathrm{E}, \times 400)$.

foods were not identified or hard to find.

We experienced a case of EoE with hypersensitivity which was induced by specific food identified through the skin testing, and improved by withholding target food.

\section{Case Report}

A 28-year-old man visited gastrointestinal clinic because of dysphagia, nausea, and substernal discomfort for 15 days. He did not have any past allergic histories and family histories of an atopic disease. Physical examination was unremarkable, and any skin lesions were not observed. The laboratory testing showed a white

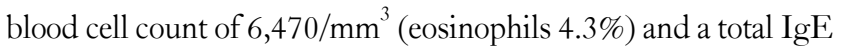
level of $147 \mathrm{IU} / \mathrm{mL}$ (Class 3). It is significant as allergen when the class values of total $\operatorname{IgE}$ are 2 or above.

Esophagogastroduodenoscopy showed some linear furrows and multiple mucosal nodularities on the lower and mid esophagus without reflux esophagitis (Fig. 1), and we took 3 specimens at the lower and mid esophagus, respectively, under suspecting EoE. We also performed multiple biopsies at the stomach and bulb of the duodenum. Whereas multiple mucosal biopsies on the stomach and duodenum were normal, heavy eosinophilic infiltration was observed on the esophageal mucosa (Fig. 2). Based on the clinical, endoscopic and histological findings, the patient was diagnosed as EoE. We found out he had eaten the food (protein complex; Myoplex ${ }^{\circledR}$, Abbott Laboratories, Abbott Park, Illinios, USA) for 2 months while he built his body. Allergic evaluations for identifying causative allergens were performed by consulting with the specialist of the allergic department. Multiple allergen simultaneous tests showed a hypersensitivity to peanut. Also, we confirmed a hypersensitivity to the protein complex (Myoplex ${ }^{{ }^{\mathbb{B}}}$ ) by intradermal injection test (Fig. 3). We first started treatment with proton pump inhibitors after endoscopic examination, but the symptoms were improved partially after 2 weeks. After we confirmed the result of biopsies, withholding treatment was added. The patient's symptoms were improved gradually since the withholding treatment. Two months later, follow-up endoscopy revealed a disappearance of linear furrows and mucosal irregularities, and mucosal biopsies showed marked decrease in eosinophil counts less than 5 eosinophils per high power field. The patient was stable without recurrence at the 1 year follow-up.

\section{Discussion}

EoE is characterized by (1) esophageal symptoms such as dysphagia, food impaction, or regurgitation; (2) eosinophilic in- 


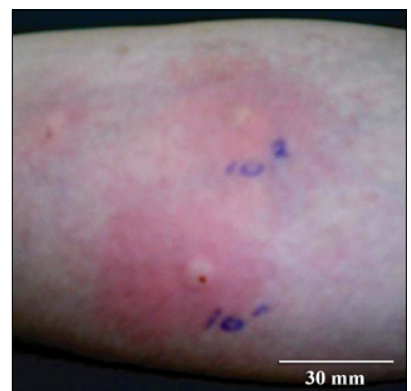

\begin{tabular}{ccc}
\hline Myoplex $^{\circledR}$ & $\begin{array}{c}\text { Wheal size } \\
(\mathrm{mm})\end{array}$ & $\begin{array}{c}\text { Erythema size } \\
(\mathrm{mm})\end{array}$ \\
\hline $1: 100$ & $7 \times 5$ & $30 \times 30$ \\
$1: 10$ & $7 \times 5$ & $35 \times 40$ \\
\hline $\begin{array}{c}\text { Histamine } \\
\text { (control) }\end{array}$ & $4 \times 4$ & $20 \times 15$ \\
\hline
\end{tabular}

Figure 3. Intradermal skin tests with protein complex $\left(\right.$ Myoplex $\left.{ }^{\circledR}\right)$ represent hypersensitivity to the dilution of protein complex compared to histamine. The size $(\mathrm{mm})$ of wheal and erythema by Myoplex ${ }^{\circledR}$ are bigger than those by histamine.

filtration at esophageal mucosa ( $\geq 15$ eosinophilis per high power field) and (3) unresponsiveness to high-dose proton pump inhibitiors. ${ }^{12}$ EoE was thought to be a common disorder in children, but recently it also has become more prevalent in adults. Although the pathogenesis of $\mathrm{EoE}$ is still not completely understood, it has been thought to relate to allergic disorders, especially food hypersensitivities. ${ }^{7}$

Food hypersensitivity reactions are divided into IgE-mediated, non-IgE-mediated and mixed ones. Whereas IgE-mediated reactions are usually immediate and mainly involve the skin, non-IgE-mediated reactions are delayed or chronic and predominantly manifest in the gastrointestinal tract and skin. IgE-mediated reactions can be confirmed by skin prick test and food specific $\operatorname{IgE}$ levels in the serum. Also, atopy patch tests are being used to detect delayed, T-cell-mediated hypersensitivity. EoE is thought to be a mixed-reaction disorder, and the combination of skin prick test and atopy patch test may be more effective to identify the causative foods. ${ }^{13}$

Therapies of EoE include drug (eg, corticosteroid) and diet treatment. ${ }^{12}$ Although the use of systemic or topical steroids improves clinical symptoms effectively, EoE recurs in more than $90 \%$ of patients after treatment is completed. ${ }^{14}$ Diet treatment can be divided into 2 categories: amino acid-based formula and elimination diet. Kelly et $\mathrm{al}^{9}$ reported the effectiveness of an amino acid-based formula in 10 pediatric EoE patients. Spergel et $\mathrm{al}^{13}$ demonstrated that 26 children with EoE improved in both symptoms and esophageal inflammation by dietary elimination of foods. Also, they recommended skin prick and atopy patch tests to identify causative foods. ${ }^{11}$ Kagalwalla et $\mathrm{al}^{10}$ also examined 60 children with EoE by a 6-food elimination diet (cow's milk, soy, wheat, egg, peanut and seafood) or an amino acid-based formula. Clinical and histological improvements were observed in $74 \%$ and $88 \%$, respectively. In adults, however, the evidence of link between food hypersensitivity and EoE was limited. In a recent study, $81 \%$ of adults with EoE had $\geq 1$ allergens identified by skin prick testing and $50 \%$ had $\geq 1$ skin tests positive to food allergens. ${ }^{15}$ The most common food allergens consisted of peanut, egg white, soybean, milk and tree nuts in their study. In our case, we suspected causative food (consist of cow's milk, egg and wheat) by history taking, confirmed it by skin testing, and achieved clinical, endoscopic and histological improvements after avoiding the food. Therefore, allergic evaluations for identifying food triggers should be recommended to all adults with EoE.

In conclusion, the link between food hypersensitivity and EoE has not been well established and there are controversies about the effectiveness of diet treatment in adult patients with EoE. Herein, we experienced a case of EoE which was induced by specific food identified through the skin testing, and improved by withholding target food. More studies are needed to demonstrate the effectiveness of diet therapy in adult patients with EoE.

\section{References}

1. Sgouros SN, Bergele C, Mantides A. Eosinophilic esophagitis in adults: a systematic review. Eur J Gastroenterol Hepatol 2006;18: 211-217.

2. Kim JW, Park JS, Kim YH, et al. Secondary achalasia by eosinophilic esophagitis. Korean J Gastrointest Endosc 2002;25:198-202.

3. Lee BJ, Park HJ, Yoon HS, Kim HK, Kim HS. Three cases of eosinophilic esophagitis with dysphagia as a chief complaint. Korean J Gastrointest Endosc 2008;36:145-149.

4. Park SB, Kim GH, Choi MK, et al. A case of eosinophilic esophagitis found incidentally during the evaluation of a gastric submucosal tumor. Korean J Gastrointest Endosc 2009;39:212-216.

5. Yu YH, Jo YJ, Jung MY, et al. Prevalence of eosinophilic esophagitis with dysphagia and reflux related symptoms in Korean patients. Korean J Neurogastroenterol Motil 2009;15:15-22.

6. Jung YM, Lee HS, Lee DH, et al. Clinical significance of incidentally detected eosinophilic esophagitis with pathologic review. Korean J Gastroenterol 2010;5 5:162-168.

7. Liacouras CA, Spergel JM, Ruchelli E, et al. Eosinophilic esophagitis: a 10-year experience in 381 children. Clin Gastroenterol Hepatol 2005;3:1198-1206.

8. Noel RJ, Putnam PE, Collins MH, et al. Clinical and immuno- 
pathologic effects of swallowed fluticasone for eosinophilic esophagitis. Clin Gastroenterol Hepatol 2004;2:568-575.

9. Kelly KJ, Lazenby AJ, Rowe PC, Yardley JH, Perman JA, Sampson HA. Eosinophilic esophagitis attributed to gastroesophageal reflux: improvement with an amino acid-based formula. Gastroenterology 1995;109:1503-1512.

10. Kagalwalla AF, Sentongo TA, Ritz S, et al. Effect of six-food elimination diet on clinical and histologic outcomes in eosinophilic esophagitis. Clin Gastroenterol Hepatol 2006;4:1097-1102.

11. Spergel JM, Beausoleil JL, Mascarenhas M, Liacouras CA. The use of skin prick tests and patch tests to identify causative foods in eosinophilic esophagitis. J Allergy Clin Immunol 2002;109:363-368.

12. Furuta GT, Liacouras CA, Collins MH, et al. Eosinophilic esoph- agitis in children and adults: a systematic review and consensus recommendations for diagnosis and treatment. Gastroenterology 2007; 133:1342-1363.

13. Spergel JM, Andrews T, Brown-Whitehorn TF, Beausoleil JL, Liacouras CA. Treatment of eosinophilic esophagitis with specific food elimination diet directed by a combination of skin prick and patch tests. Ann Allergy Asthma Immunol 2005;95:336-343.

14. Helou EF, Simonson J, Arora AS. 3-yr-follow-up of topical corticosteroid treatment for eosinophilic esophagitis in adults. Am J Gastroenterol 2008;103:2194-2199.

15. Penfield JD, Lang DM, Goldblum JR, Lopez R, Falk GW. The role of allergy evaluation in adults with eosinophilic esophagitis. J Clin Gastroenterol 2010;44:22-27. 